\title{
Undrained Monotonic and Cyclic Response in Thickened Tailings
}

\author{
L.A. Cifuentes Arcadis, Chile \\ R. Verdugo Universidad de Chile, Chile
}

\begin{abstract}
A series of tests were performed to characterise the undrained monotonic and cyclic response of integral tailings, using CIU triaxial and isotropically consolidated cyclic triaxial tests at different confining stresses. The samples were obtained from thickened tailings 'manufactured' and deposited in the laboratory at 72\% concentration of solid particles and from samples prepared through moist tamping. With this data, the influence of the 'fabric' or sample preparation on the undrained monotonic and cyclic behaviour of the tailings will be evaluated. Finally, the results indicate that the thickened tailings tested are susceptible to liquefaction.
\end{abstract}

\section{Introduction}

In order to decrease fresh and recirculated water consumption in mining, conventional thickeners have usually been used in the process of tailings generation, reaching concentrations of solid particles of around $50 \%$. However, the requirements of the new mining projects (production increase and environmental restrictions in the use of water) have led to the development of new technologies of more efficient thickening methods such as powerful thickeners and flocculants, increasing water reclaim and the capacity of tailing impoundment.

Robinsky (1999) has defined 'thickened tailings', depending on the water content, consistency, strength, and/or pumping and transport system, ranging from high density thickened, pastes, to filtered tailings (Jewell et al., 2002).

Some operational advantages of thickened tailings (Robinsky 1999), are:

- Decrease of available water for infiltration into the natural ground.

- Homogeneous material that does not segregate during transport and deposition.

- Feasibility of partial closure stages by sectors in the impoundment.

Another advantage is the posibility for disposition on non-horizontal beach slopes, allowing an increase in the storage capacity of the impoundments. This condition leads to this material being part of the stability of the impoundments as shown on Figure 1.

In Chile, the conventional thickened tailings are deposited with a high moisture content, segregating and consolidating slowly (Verdugo, 2004), leaving thin layers (slime) of loose material, with low shear resistance, and with few possibilities of participating as a resisting element in the stability of the dams (Figure 2).

Finally, the use of this new technology is limited by the lack of geotechnical research that allow for the assurance of the stability of the impoundments in the long term (Poulus et al., 1985), for static and seismic conditions. This is very important in a high seismicity country like Chile. 


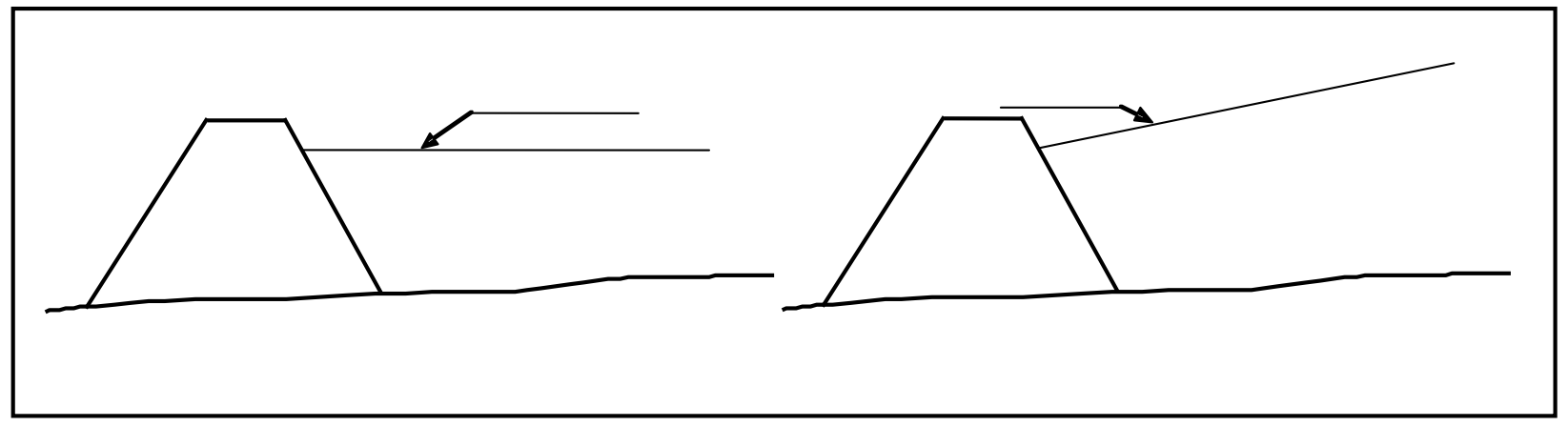

\section{Figure 1 Difference in the deposition of conventional and thickened tailings}

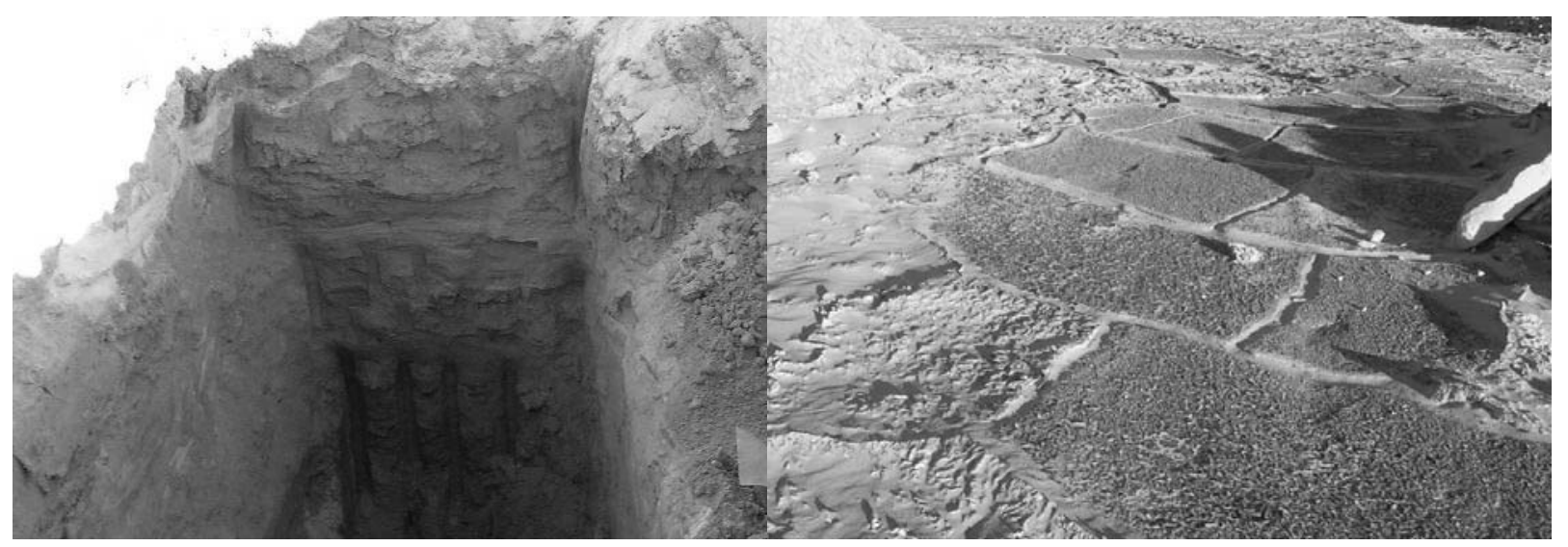

Figure 2 Stratified and segregated deposition of a conventional tailings impoundment

\section{Methodology}

\subsection{Sampling}

A sample of integral tailings from the Ovejeria tailings impoundment, was obtained before cycloning from one of its transport channels, as shown in Figure 3. It was sampled with a bucket and deposited in plastic containers. According to the information obtained in the field during the sampling, the concentration of solid particles of the sample would be around 55\%. At this concentration, the segregation of the particles is expected once the transport velocity decreases, as is evidenced by the dry material of an adjacent channel, shown in Figure 4. In this channel, the surface cracking by drying associated with materials with a high fine content on top is observed.
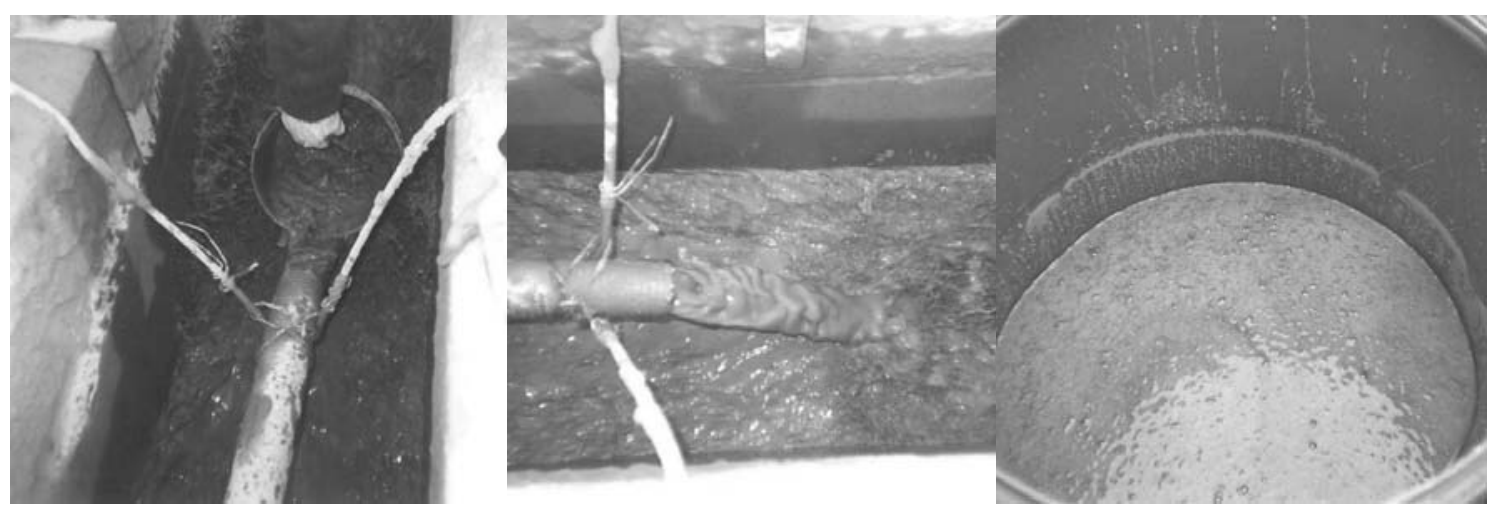

Figure 3 Aspect of the tailings sampled from the channel. Ovejeria tailings impoundment 


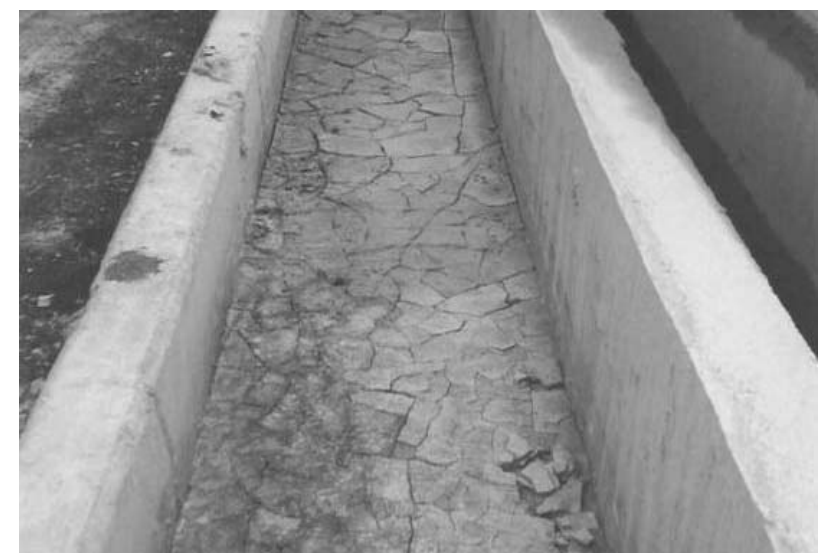

Figure 4 Tailings in the transport channel in a dry state with surface cracking

On the other hand, the surface deposition of high density thickened tailings is a technology that has been recently considered for study by the national mining industry. Therefore, it was not possible to obtain representative undisturbed samples for the present work.

\subsection{Sample preparation}

At the laboratory, the saturated material was allowed to decant enough time such that solid particles sedimented completely and the extraction of water from the surface did not eliminate the finer particles. Later, the material was allowed to air dry and was separated until obtaining dry sandy silt.

With the purpose of simulating a sample of undisturbed high density thickened tailings disposal in surface, a thickened tailing was prepared without the use of flocculants. A concentration of solid particles of $72 \%$ was reached. Then, it was deposited in an acrylic box.

Dimensions of the box were 75 and $35 \mathrm{~cm}$ of base and $25 \mathrm{~cm}$ of height, totally coated with a thin layer of lubricant on internal walls (Figure 5). At the base of the box, a drain layer was placed composed of filter paper and coarse sand, to allow moisture loss by evaporation from the top surface and by drainage from the bottom. The appearance of the deposited and dry tailings is observed on Figure 6. During the drying process the material, contracted in a homogeneous way without generating contraction cracks at its surface, which allowed for the visual estimate that a non-segregated material deposition was generated.

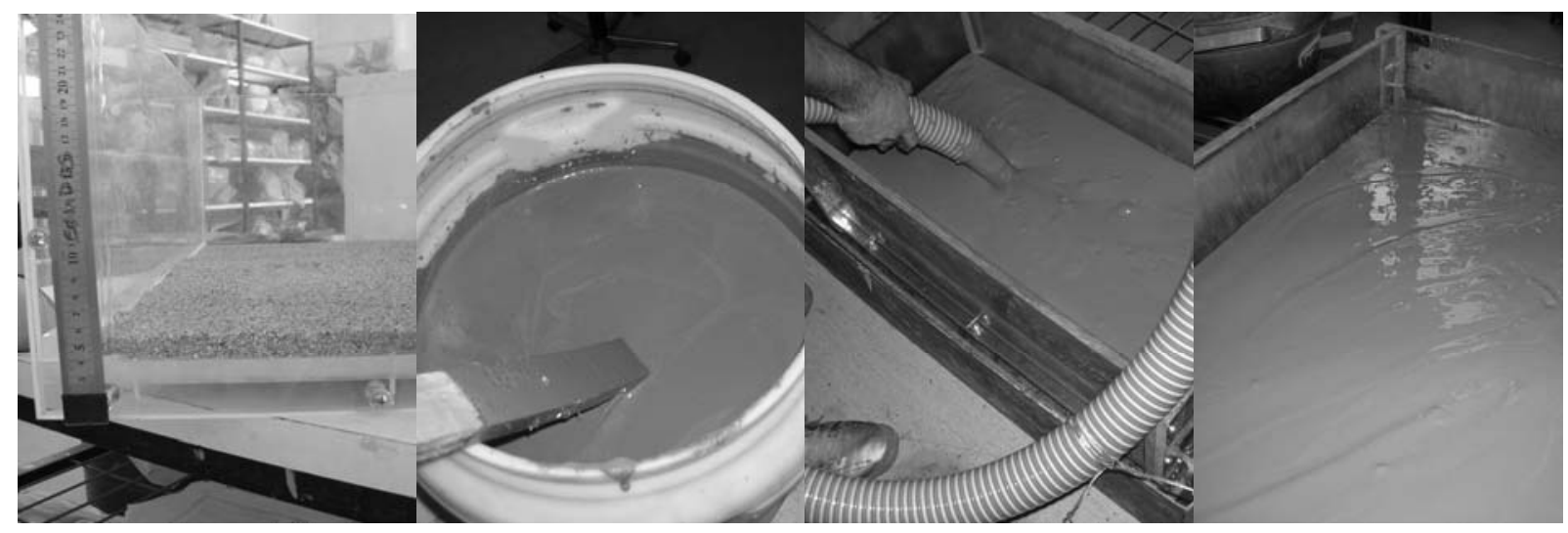

Figure 5 Manufacturing of thickened tailings at a $72 \%$ of solids concentration 


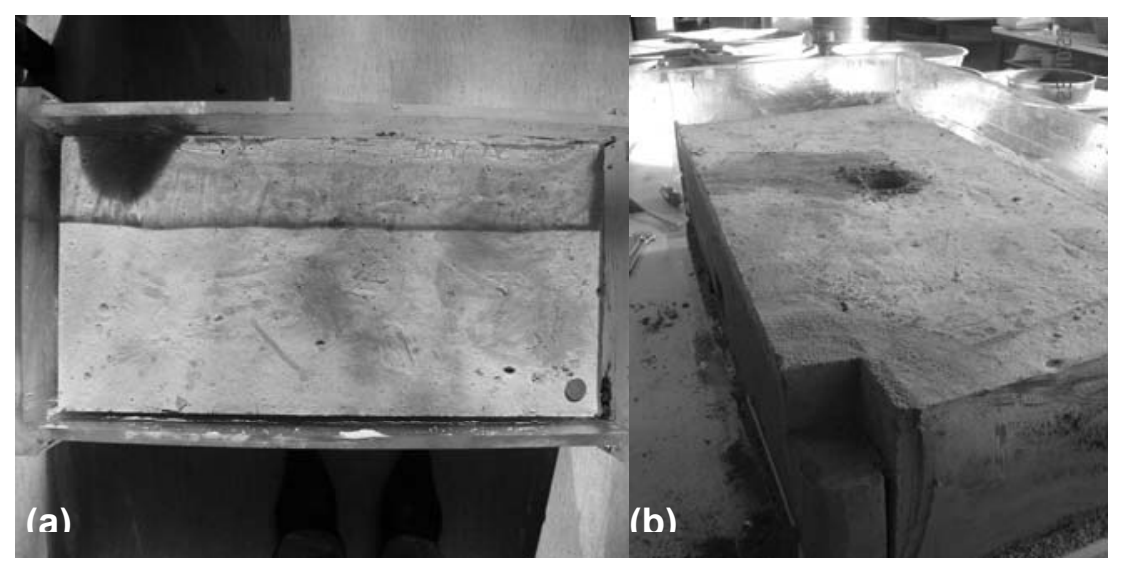

Figure 6 Appearance of the deposited dry tailings: (a) top view, (b) side view

\section{Index properties determination}

Tests were performed to determine the index properties of the tailings, such as: grain size distribution by sieving and hydrometer, Atterberg Limits (liquid, plastic, and contraction), and specific gravity. To evaluate the level of densification, Modified and Standard Proctor and maximum and minimum density tests were performed according to ASTM, NCh, and Japanese standards. The summary of these results is shown in Table 1.

Table 1 Summary of results of tests for index properties of integral tailings

\begin{tabular}{ll}
\hline Maximum Particle Size & $\mathbf{2 . 0 0} \mathbf{~ m m}$ \\
\hline Percent fines $(<0.074 \mathrm{~mm})$ & $56 \%$ \\
$\mathrm{~d}_{60}$ & $0.092 \mathrm{~mm}$ \\
$\mathrm{~d}_{30}$ & $0.016 \mathrm{~mm}$ \\
Percent of material under $0.02 \mathrm{~mm}$ & $34 \%$ \\
Specific gravity, $\mathrm{G}_{\mathrm{s}}$ & 2.75 \\
Liquid limit, $\mathrm{w}_{\mathrm{l}}$ & 19 \\
Plastic limit, $\mathrm{w}_{\mathrm{p}}$ & $\mathrm{s} / \mathrm{n}$ \\
Contraction limit, $\mathrm{w}_{\mathrm{c}}$ & 14.5 \\
USCS classification & $\mathrm{ML}$ \\
Maximum dry density of compaction (M.P.) & $2.056 \mathrm{t} / \mathrm{m}^{3}$ \\
Optimum moisture of compaction (M.P.) & $10.0 \%$ \\
Maximum dry density of compaction (S.P.) & $1.959 \mathrm{t} / \mathrm{m}^{3}$ \\
Optimum moisture of compaction (S.P.) & $12.5 \%$ \\
Maximum density by vibration (J.M.) & $1.586 \mathrm{t} / \mathrm{m}^{3}$ \\
Minimum density (J.M.) & $1.087 \mathrm{t} / \mathrm{m}^{3}$ \\
\hline Notes: (M.P. and S.P.) Modified Proctor and Standard Proctor & \\
(J.M.) Japanese method &
\end{tabular}

Based on these results, the integral tailings classify as non-plastic sandy silt (ML according to the USCS classification). Material under $0.02 \mathrm{~mm}$ was equivalent to $34 \%$, which is larger than the minimum quantity recommended (by various authors) for the preparation of a thickened tailing without segregation. 
The segregation would be avoided with the thickened tailings, given the limited water content to form it, behaving like a homogeneous material (Robinsky, 1999; Crowder et al., 2002; Grabinsky et al., 2002). The formation of the thickened tailings is facilitated when the material under $0.02 \mathrm{~mm}$ is greater than $15 \%$, as indicated by Crowder et al. (2000).

The density measurement indicated that the samples taken from the 'lab manufactured' sample showed compaction percentages that were around 84 and $88 \%$ of the maximum dry density with respect to the Modified and Standard Proctor tests, respectively. These values are indicative of a medium to low compaction.

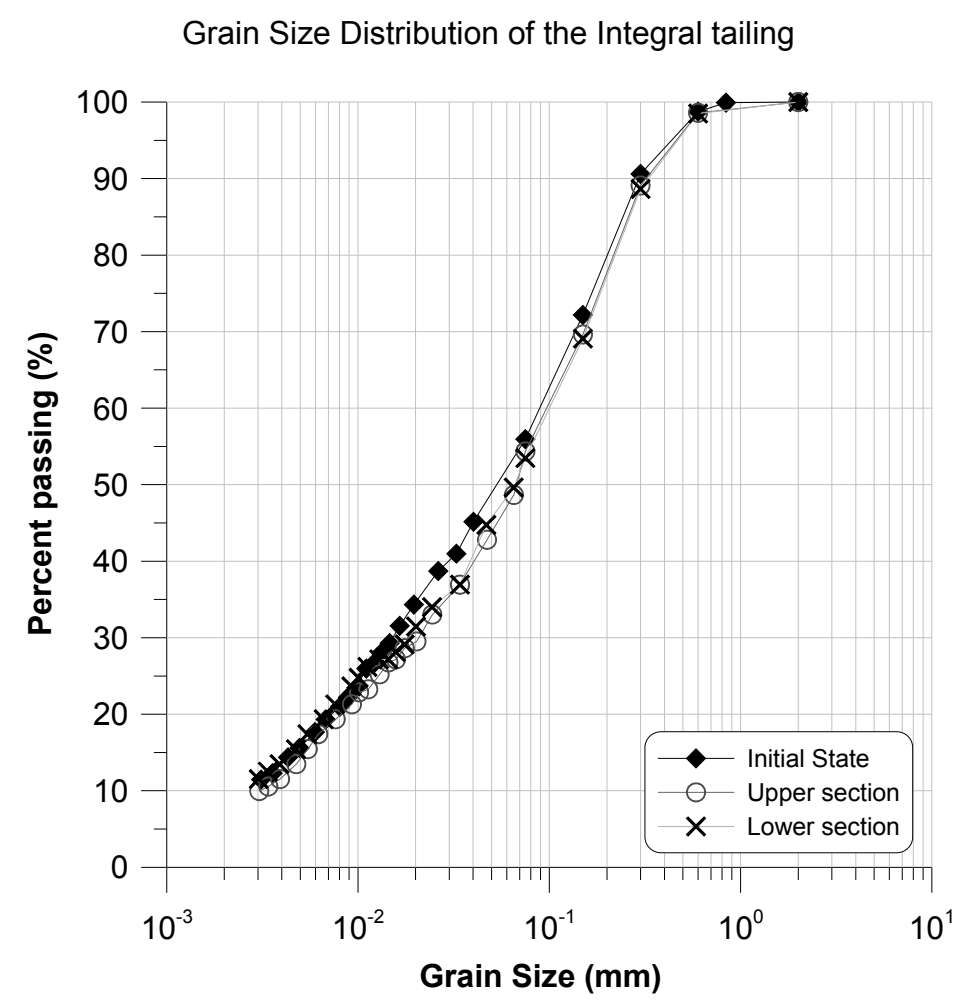

Figure 7 Grain size distribution of the samples

In order to evaluate possible segregation of the 'lab manufactured' tailings, grain size by sieving and hydrometer tests were performed, on the upper and lower sections of the sample. Results are presented in Figure 7. It is observed that the particle distribution is similar, hence it is possible to conclude the sample is homogenous without segregation.

\section{CIU triaxial tests}

The effect of the initial fabric was analysed by performing CIU triaxial tests analyse on samples prepared by two methods: deposition in a box and moist tamping. Samples of the box were obtained from the thickened tailings cut in a dry state. The remoulded samples (moist tamping) were compacted in five layers at similar dry densities of the tailings deposited in the box. In this preparation, moisture content was close to $10 \%$ ( $85 \%$ of the Modified Proctor). Besides, some samples at densities 90 and $95 \%$ of the Modified Proctor were also included. The isotropic confining stresses used in tests were: $0.5,1.0,2.0$ and $3.0 \mathrm{~kg} / \mathrm{cm}^{2}$. In all tests, it was verified that the B-values (saturation index) were greater than $95 \%$. The voids ratio was calculated after consolidation, through the determination of the dry weight and final moisture content, at the end of each test (Verdugo and Ishihara, 1996). 

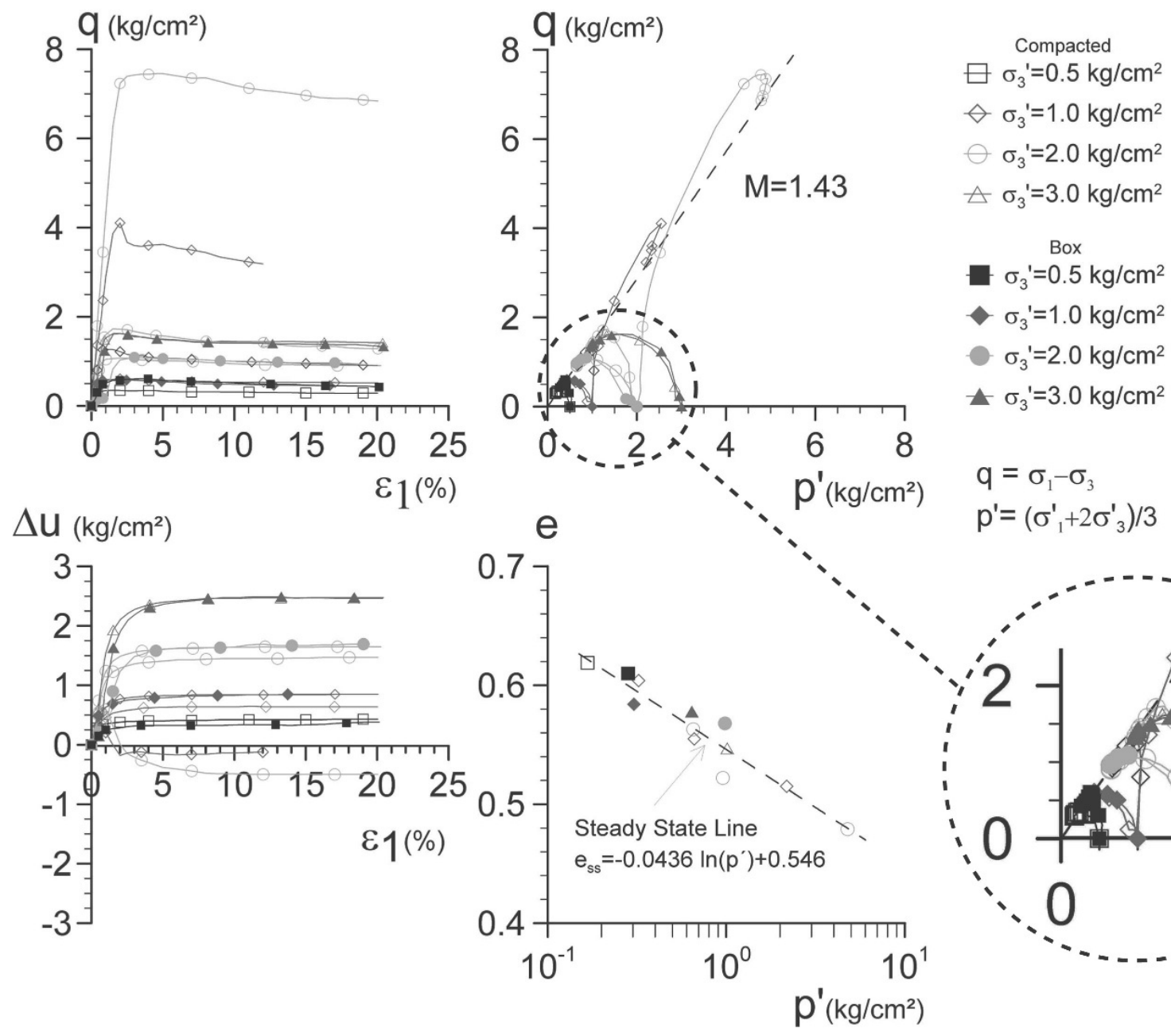

$q=\sigma_{1}-\sigma_{3}$

$\mathrm{p}^{\prime}=\left(\sigma_{1}^{\prime}+2 \sigma_{3}^{\prime}\right) / 3$

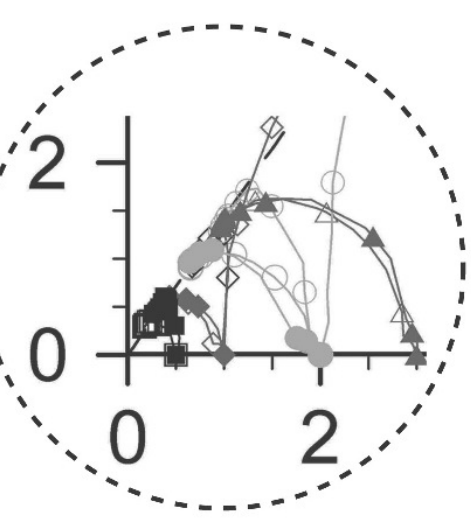

\section{Figure 8 Results of the CIU triaxial tests on undisturbed manufactured and remolded samples of thickened tailings}

Figure 8 shows the stress path and the q- $\varepsilon$. curves obtained from the CIU triaxial test. As expected, the samples of lower densities showed a contractive behaviour, while the denser samples presented a dilative response. It is important to observe that these later samples presented local failure at the end of the test. On the other hand, in all tested samples, the failure envelope is the same independently of the initial fabric and density (Ishihara, 1993; Verdugo and Ishihara, 1996). In the p'-q plane the failure envelope has a slope equal to 1.43 .

The box samples have a monotonic undrained contractive response, similar to the remoulded samples at a similar density and become potential generators of flow failure. For initial confining stresses from 1.0 $\mathrm{kg} / \mathrm{cm}^{2}$, stress paths are similar, indicating that over the initial stress, the undrained shear stress is independent of the initial 'fabric'. Figure 9 shows this situation.

In the box samples attempting to reproduce real conditions of deposition and drying of the tailings, it is possible to estimate a relation between the undrained shear stress $\mathrm{Su}$ and the initial confining stress p' ${ }_{0}$ as: $\mathrm{Su} / \mathrm{p}_{0}=0.237$.

In general, the samples obtained from the box and the remoulded samples, compacted at similar densities, present a normally consolidated behaviour, independent of the initial fabric. 


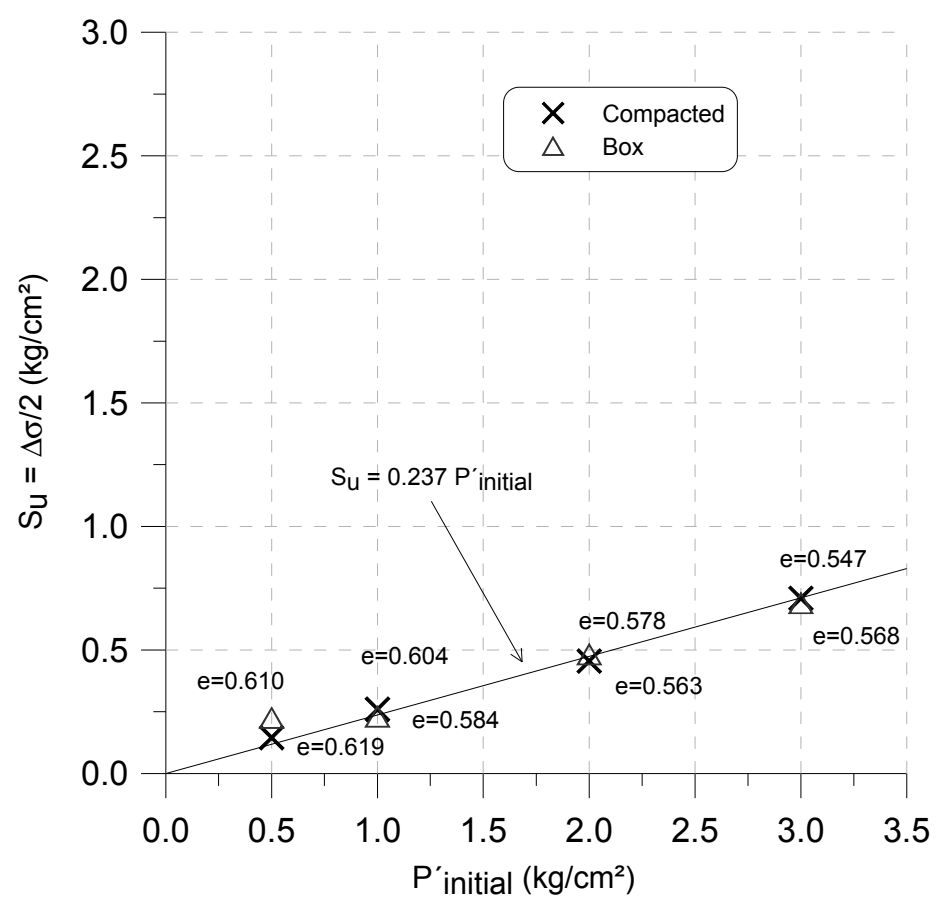

Figure 9 Undrained shear stress from different samples

\section{$5 \quad$ Isotropically consolidated undrained cyclic triaxial tests}

To evaluate the cyclic response, isotropically consolidated undrained cyclic triaxial tests were performed on samples obtained from the box and on samples remoulded at similar densities. The confining stresses used were 1.0 and $3.0 \mathrm{~kg} / \mathrm{cm}^{2}$. In all the tests, it was verified that the B-value, was greater than $95 \%$. The voids ratio was measured after the consolidation with the same procedure used in the CIU triaxial tests. The cyclic stresses (Rc) applied were selected so as to cover the greatest possible range of cyclic loading.

The cyclic resistance curves were obtained from the evaluation of the number of cycles to reach a deformation of double the amplitude (D.A.) of 5 and $10 \%$ and for an increase in pore pressure $(\Delta \mathrm{u})$ equal to the initial effective stress. These curves are shown in Figure 10.

Results show that for $1.0 \mathrm{~kg} / \mathrm{cm}^{2}$ of initial confining stress, the box samples showed a greater cyclic resistance than remoulded ones at the same density. While for the samples tested at $3.0 \mathrm{~kg} / \mathrm{cm}^{2}$, the cyclic resistance is independent of the initial fabric. On the other hand, the cyclic resistance curve for the remoulded samples at $1.0 \mathrm{~kg} / \mathrm{cm}^{2}$ is similar to the samples at $3.0 \mathrm{~kg} / \mathrm{cm}^{2}$.

The results obtained allows to conclude that after a certain level of effective stress, greater than $1.0 \mathrm{~kg} / \mathrm{cm}^{2}$, the samples of consolidated thickened tailings do not present an important increase of the cyclic resistance, if the samples are obtained from a manufactured deposit. On the other hand, for the CIU triaxial tests, it is established that for samples tested at an effective stress greater than $0.5 \mathrm{~kg} / \mathrm{cm}^{2}$, the undrained monotonic response was independent of the fabric, which represents a limit stress lower than what was estimated from the cyclic tests.

The cyclic resistance curves were evaluated for a 5 and $10 \%$ of double amplitude of deformation. No important differences were observed between them. This result reflects that these materials reached deformations close to $5 \%$, great deformations associated with a double amplitude of $10 \%$ are produced almost immediately, independently of the initial fabric. In effect, the deformation curves, as the diverting stress is applied, show a low speed deformation increase with the cyclic loading, which abruptly increases when these are greater than $1 \%$. 

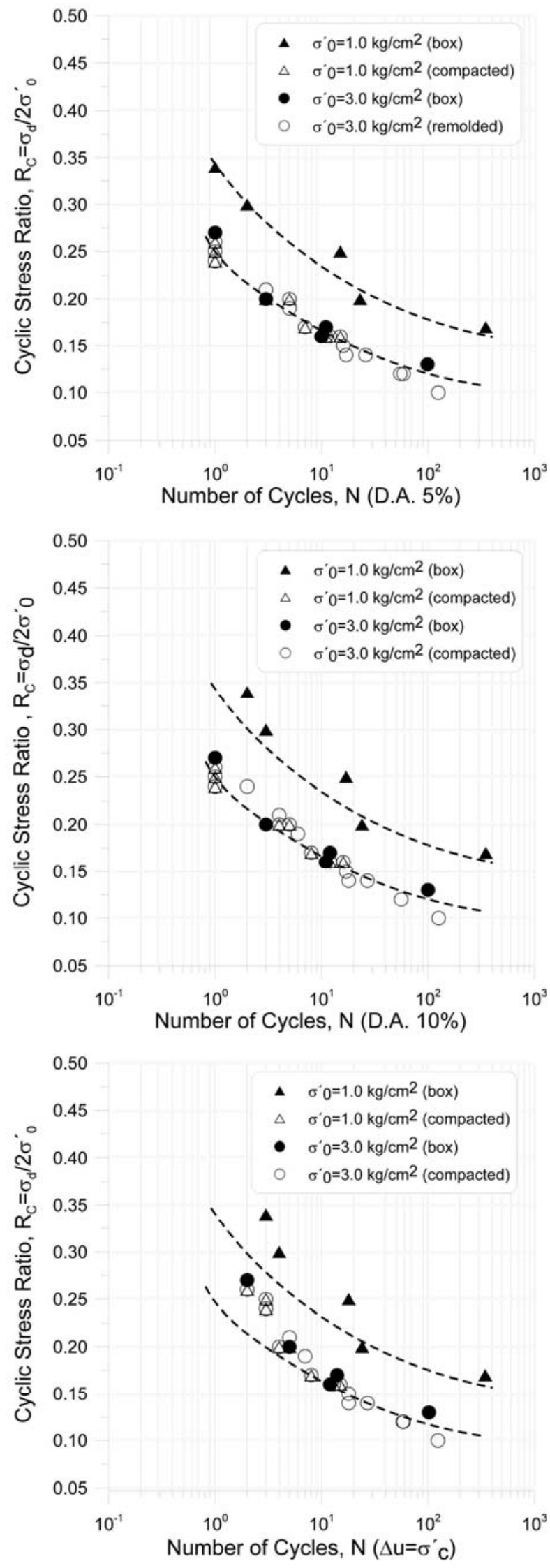

Figure 10 Cyclic resistance curves for double amplitude of $5 \%$ (a), for double amplitude of $10 \%$ (b), and for $\Delta \mathrm{u}$ equal to the initial confining stress (c) 


\section{Conclusions}

The main conclusions are:

- A deposition process in a box was done with thickened tailings at a $72 \%$ of solid particle concentration. The level of material segregation was evaluated through a grain size distribution analysis of the upper and lower sections and no major differences were observed. Non segregation was estimated in the deposited sample.

- The tailings tested correspond to non-plastic sandy silt (ML), with a fines content of 56\%. The material under $0.02 \mathrm{~mm}$ is $34 \%$, making it possible to form high density tailings that do not segregate.

- Dry densities achieved in the box were 84 and $88 \%$ of the Modified and Standard Proctor, respectively. These values indicate a low densification.

- In the CIU triaxial tests, samples of the box and those remoulded at similar densities present a contractive undrained monotonic behaviour. At low initial confining stresses, the response is affected by the initial fabric condition that is removed in the samples tested over $1.0 \mathrm{~kg} / \mathrm{cm}^{2}$. The initial drying improves the undrained resistance at low confining stresses with a slight preconsolidation. The monotonic response of the samples at larger confining stresses is normally consolidated.

- In the CIU triaxial tests, samples obtained from the box and those compacted at different densities indicate that the failure envelope is independent of the initial fabric.

- In the undrained cyclic triaxial tests, samples tested at $1.0 \mathrm{~kg} / \mathrm{cm}^{2}$ showed a different response according to the initial fabric, the box samples presenting greater resistance. For a testing stress of $3.0 \mathrm{~kg} / \mathrm{cm}^{2}$, the effect of the initial fabric is lost, all the results being similar. Consequently, for confining stresses greater than $1.0 \mathrm{~kg} / \mathrm{cm}^{2}$, the cyclic response of the tailings tested for the present investigation could be tested by remoulded samples with previous knowledge of the in-situ densities.

- A high density thickened tailings may present a contractive response (flow failure) and cyclic mobility if the conditions of saturation and stress allow it. Therefore, the assurance of the static and seismic stability of high density thickened tailings must be studied on a case by case basis.

\section{Acknowledgements}

This study is part of the thesis for the Master of Science in Engineering Degree of Loreto Cifuentes at the University of Chile. The authors are pleased to acknowledge the MECESUP laboratory assistance, mainly to Omar González. Figures were prepared by Marcia Cifuentes.

\section{References}

Biarez, J. and Hicher P. (1994) Elementary mechanics of soil behaviour, saturated remoulded soils, AA Balkema.

Crowder, J.J., Grabinsky, M.W. and Klein, K.A. (2002) Laboratory characterization of tailings paste for surface disposal, Proceedings of the 55th Canadian Geotechnical Conference, Niagara Falls, Ontario, Canada, October.

Crowder, J.J., Grabinsky, M.W.F. and Landriault, D.A. (2000) Consolidation testing and s.e.m. images of tailings pastes for surfaces disposal, Proceedings of 53rd Canadian Geotechnical Conference, Montreal, Quebec.

Grabinsky, M.W., Theriault, J. and Welch, D. (2002) An overview of paste and thickened tailings disposal on surface, Symposium on Mine Waste and the environment, Rouyn-Noranda.

Ishihara, K. (1993) Liquefaction and flow failure during earthquakes, Geotechnique 43 N³, pp. 351-415.

Jewell, R.J., Fourie, A.B. and Lord, E.R. (eds), (2002) Paste and Thickened Tailings - A Guide, Australian Centre for Geomechanics, Perth, Australia, 256 p.

Poulus, S.J., Robinsky, E.I. and Keller T.O. (1985) Liquefaction resistance of thickened tailings, Journal of Geotechnical Engineering División, ASCE, Vol. III, N¹2, pp. 1380-1394.

Robinsky, E.I. (1999) Thickened tailings disposal in the mining industry, E.I. Robinsky Associates Limited, Toronto, Canada.

Theriault, J.A., Frostiak, J. and Welch, D. (2003) Surface disposal of paste tailings at the Bulyanhulu gold mine, Tanzania, Proceedings of Sudbury Mining and Environment, on CD-ROM. 
Verdugo, R. and Ishihara, K. (1996) The steady state of sandy soils, soils and foundations, Vol. 36, No. 2, pp. 81-91.

Verdugo, R. (2004) Seismic behaviour of tailings dams, Charla especial, 5to Congreso Colombiano de Geotecnia, Bogotá, Colombia.

Whitlow, R. (1999) Fundamentos de mecánica de suelos, Editorial CECSA. 